\title{
Grade 3 Mathematics Barriers: Why Learners Experience Them?
}

\author{
Dr Maphetla Magdeline Machaba, University of South Africa
}

\begin{abstract}
The aim of this paper is to discuss the barriers that learners encounter when learning mathematics and to explore an approach that will simplify the teaching of mathematics in Foundation Phase. A qualitative research design within the interpretive paradigm was used. Five professionally qualified Grade 3 mathematics teachers were sampled from five primary schools in the Tshwane South District in South Africa. The data was collected through lesson observation, interviews and focus groups. The data was analysed by reading transcripts to identify patterns that emerged from the data; these patterns were developed into categories. The participants in this study included Grade 3 mathematics learners. Grade 3 learners were selected because they have already done all the mathematics computations. The research revealed that the main barriers to understanding mathematics relate to language, an inability to solve word sums, being unable to carry over to the tens/hundreds, and confusing multiple signs and addition signs. Recommendations were that the teachers should not handle too many aspects at any given time. Until the teachers are sure that the learners have mastered one element or function, such as addition, they should not move to the next section.
\end{abstract}

Keywords: Foundation Phase, Mathematics Barriers, Grade 3; Learners

$\begin{array}{lll}\text { Received: 22.11.2020 } & \text { Accepted: 11.12.2020 } & \text { Published: 10.01.2021 }\end{array}$

\section{INTRODUCTION}

The importance of mathematics as a subject can never be over-emphasised, especially in today's technological society. Modern science and technology depend increasingly upon mathematics and many occupations require a certain degree of mathematical knowledge and skills. The fact, however, is that mathematics is generally considered a difficult subject. Many people fail to master the subject.

Historically, the purpose and importance of mathematics learning in the early years has not been properly understood or valued in South Africa. This is in part because there is not a general understanding of how mathematical ideas and skills are developed between birth and five years, nor of how best to approach the teaching and learning of key concepts and competencies during this period National Council for Curriculum and Assessment (NCCA) (2011). This report seeks to fill that gap, by providing both a conceptual overview and practical framework for early mathematics development. It is aimed at all those involved in the Foundation Phase sphere and will be a useful resource for Foundation Phase teachers, practitioners, trainers and planners, as well as parents, carers and home visitors.

In the period before they begin school, which is five turning six years of age in South Africa, children are in a variety of early years' settings. Most are cared for during the day in the home, with a minority of these children benefiting from visits from community workers such as home visitors. Some children attend preschool or crèche while their parents are at work and others participate in community-based services such as playgroups or parent groups. It is a well fact that South African children underperform significantly in language and mathematics. A high percentage of learners are fail to achieve even the minimum expected standards in these core subjects Department of Basic Education (2012). International data indicate that even when compared with low-income countries in Africa, South Africa compares poorly on tests of mathematics. The reasons for this are complex and rooted in factors that go well beyond the classroom and that affect children's development and wellbeing from birth.

\section{STATEMENT OF THE PROBLEM}

South Africa has been trying to address the problem of providing high quality education through, among other things, emphasizing the use of local languages as medium of instruction in Grade 1 to 3 and English thereafter (Department of Basic Education (2012). However, some teachers have expressed doubts about the wisdom of a local language medium policy in a multilingual country like South Africa in which a language of wider communication such as English is the official language (Adler 2001; Morgan 2000; Bressoud, Mesa, \& Rasmussen 2015). Some critics argue that there is hardly any empirical justification for the superiority of a local language medium over English medium (Park 2016). 
However, the most recent studies on language of instruction in Gauteng Province have focused on a socio-linguistic approach, (Males, Earnest, Dietiker, \& Amador (2015), even though, these studies were not conducted in the classroom. Yet teachers may experience some classroom communication problems, which may impede the use of Sepedi in the classroom. In particular, considering the various teacher characteristics, teachers may have knowledge and practices about the use of Sepedi in mathematics. However, different teachers may perceive mathematics as a subject demanding a different language because different subjects may elicit different linguistic demands.

Teachers may also be ill prepared to use Sepedi in mathematics. Teachers' lack of awareness of mathematical register or terminology in Sepedi may make it difficult for them to discuss mathematics in the classroom. Consequently, teachers may have more effective English language skills than Sepedi. These and many more problems may create dilemmas and tensions in the teachers, which may affect the teachers' performance in the use of language in mathematics teaching. In the absence of research data on the use of Sepedi and English in mathematics lessons in the Foundation Phase schools in Gauteng, it is very difficult to ascertain how teachers use Sepedi or English in mathematics. How do teachers feel about it? Do they use English better than the local language in teaching mathematics?

Does it matter to the teachers whether they use a local language or English in the way they bring to the surface the language skills in mathematics teaching? Many classroom discourse analyses have been done on a single language medium and in other subjects more than in in the mathematics teaching process (Amador \& Weiland 2015). Therefore, there was a need to conduct a study to find out how teachers use local languages and English in mathematics teaching in the Foundation Phase schools in South Africa.

\section{SIGNIFICANCE OF THE STUDY}

Language is one of the tools for communicating about the world. Thoughts are expressed in language. Language is used in everyday life to transmit culture and social knowledge, attitudes and values. It is against this background that adequate understanding of how language is used in schools is perceived to be absolutely essential Bressoud, Mesa, \& Rasmussen (2015).

One objective of basic mathematics education must surely be to ensure an understanding of mathematics in the children. In most countries, mathematics dominates the Foundation Phase school curriculum. An adult usually introduces mathematics when the child is still developing language Sintema \& Phiri (2018). In order to carry out this objective, teachers must first understand how the language of instruction may interfere with the child's learning of mathematics and then investigate how teachers use language to enhance construction of knowledge.

Different languages carry different conceptual meanings in mathematics because concepts develop with the need in the sociolinguistic group. The group develops a language for communicating the concept and the language becomes part of the subject content Sintema \& Phiri (2018). This process of developing a language based on the need for use and for communication is different in different societies and it must be understood in the social context of the user. The use of a language in teaching and learning mathematics will only be meaningful if the underlying implications for learners' understanding of mathematics are understood. It is essential to study how teachers use language in mathematics teaching so as to relate the findings to how children construct knowledge.

A study on the use of Sepedi in teaching and learning of mathematics has not previously been carried out in Gauteng Province. Even the few studies in developed countries in this area have concentrated on the language issue in terms of minority versus majority, immigrants versus locals, advantaged versus disadvantaged, middle class versus low or high class children (Tooke, Hyatt, Leigh, Snyder \& Borda, 2015). It is hoped that, the design of the present study, will produce clearer evidence of teacher efficiency in using language skills in mathematics teaching.

This study is unique in a number of ways. It is based on my experience in teaching mathematics at school level, designing and developing curricula and curriculum materials for schools, initiating and conducting research in mathematics education in schools and in service training of Foundation Phase school teachers and teacher trainers in mathematics education since 1984. It is partly this knowledge and experience that has formed the basis for raising the research questions for this study.

The scope of the study allows me to critically investigate how mathematics teachers are use Sepedi, a local language, in school and to compare its use with English, the foreign language medium. Research in the area of how a local language is used by both teachers and learners is scarce. Therefore, the findings of the study are exclusive and innovative because Gauteng Province is a multilingual country with a bilingual policy in education together with educational and sociolinguistic contexts different from those in other countries. 


\section{THEORIES AND PRACTICES OF CLASSROOM COMMUNICATION FRAMEWORK}

The study is theoretically based in constructivism. The general perception of constructivism has developed considerably over recent years and a theory of teaching and learning mathematics (Thompson, 2016). The conversation of constructivism will largely trace its applicability in understanding teaching as a communication process with the main focus on the role played by language use in helping learners in constructing their knowledge. Constructivism is a philosophical perspective on knowledge and teaching and learning. It has its origin in 18th Century, more recently through the work of Piaget, (1997) and Vygotsky, (1995) and has influenced many of the curricula and classroom practices in the world today.

Modem constructivism is derived from the works of Piaget who was both a constructivistic epistemologist and a developmental psychologist whose work has influenced teaching and learning activities. Piagetian theory of constructivism can be understood through cognitive adaptation in terms of the learner's assimilation and accommodation of experience into action schemes Piaget, (1997). Piagetian theory appears to me to fit the observed facts about children's learning more satisfactorily than any other theory.

My main interest in constructivism is in its relation to teacher use of language to help learners construct mathematics knowledge; I shall pursue those aspects of constructivism, which relate to my area of interest. The first principle says that knowledge is actively constructed from the environment. This principle can be perceived in Vygotskian theory of learning, as the learners' understandings is dependent on prior knowledge and experiences (Males, Earnest, Dietiker, \& Amador (2015).

In constructivism, teachers and learners are considered as meaning makers who give contextually based meanings to each other's words and actions as they interact. Because teachers and learners each construct their meanings for words and events in the context of the on-going interaction, it is readily apparent why communication often breaks down, why teachers and learners frequently talk past each other. The constructivist's problem is to account for successful communication in the classroom, which requires some attention to the social context of that communication Stipek, Oivvin, Salmon, and MacGyners, (2001).

The theory of constructivism seems to require a move from a purely individual view of knowledge construction to one in which the social processes of discussion and negotiation have a significant role to play. Briggs, Cochran, \& Gillett (2015), identified two key features of social constructivism, that there is the active construction of knowledge and that there is the essential role played by experience and interaction with the physical and social worlds, in both physical action and speech modes. A third feature suggests that reality is constructed intersubjectively; it is socially negotiated between significant others who are able to share meanings and social perspectives of a common lifeworld (Briggs, Cochran, \& Gillett 2015).

This view of constructivism recognises among others, the role of language in knowledge construction (Hunter, 2005). In the social environment, other individuals who have a powerful role to play, challenge a human learner. Through use of language and social interchange individual knowledge can be challenged and new knowledge constructed (Hunter, 2005). Moreover, there comes a shared or common or intersubjective knowledge.

\section{LITERATURE REVIEW}

\section{Mathematical knowledge and vocabulary}

Researchers in education have been concerned with the theoretical perspective of how language is related to mathematics learning (Sintema \& Phiri, 2018; Stipek, Oivvin, Salmon, and MacGyners, 2001). The central issue has been that mathematical concepts and principles that are the basic learning blocks, are communicated usually in language. In all languages, there are special terms that describe specific mathematical concepts and are referred, to as mathematics vocabulary or mathematics registers (Martin 2007).

Children learn mathematical concepts through words and symbols. At Foundation Phase school level, children learn and use symbols like + (add), $x$ (multiply), - (divide) and (subtract). Letters of the alphabet are sometimes used as mathematical symbols. For example, $3 a=12$ and $3 \times 4=12$. Making combinations of letters or mathematical symbols or both, for example, 33, forms mathematical words. Of course the longer the combination, the more difficult the word is. When presented with an unfamiliar word in ordinary reading, the reader can use word-analysis skills to break the word down into parts.

This is not easy in mathematics. The learners must recognise and understand the mathematical relationship between the components of the word. For example, in 33, the learners must see the first 3 as 3 tens and the second 3 as 3 ones. Children learn the concepts in mathematics by constantly coming into contact with them, and symbols that describe the concepts. 
Words with special emphasis in mathematics include how many, how many more, the difference, altogether, which take a special meaning in mathematics. For example, what is the difference between 38 and 74 would mean subtract 38 from 74 in mathematics, which is different from the ordinary use of the words. In ordinary use, 'what is the difference between 38 and 74 would mean describing the physical appearances that make the two numbers different such as one having a three whereas the other one has not.

Technical vocabulary in mathematics may present problems of three different kinds (Phajane, 2017). First, the word may entirely be new. The learners may be unable to pronounce the word or to use word analysis skills. Second, the concept represented by the word may be new. Third, the concept represented by the word, such as 'numbers' and 'addition' may have no simple concrete referent (Phajane, 2017).

Another confusing factor in vocabulary development is that basic words, can be presented in different forms. The learner has to recognise different pronunciation as well as identify differences in meaning. An example of this potential problem is found in the variations of the word 'multiply'; that is multiplier, multiplication, and multiplicand. A final area of potential difficulty is the use of the abbreviations and special symbols. Numbers are all represented by symbols such as 1, 2, 3 and 4 . Yet children are required to read, recognise and perceive them as concepts of quantities.

Phajane, (2017) reports the lack of understanding of common mathematical terms employed by 13-year-olds of average ability. The word "multiple" was misunderstood by the majority of learners and similar misunderstandings occurred with respect to geometrical terms. Stewart, (2015) argues that the misunderstanding might have been due partly to the fact that many mathematical terms are used also in colloquial speech. The way language development interacts with the growth of mathematical understanding is another subject to which psychologists have paid considerable attention.

Questions have been raised, as to whether the growth in linguistic ability, follows the development of concrete operational thought or whether in fact the development of adequate terminology is a prerequisite for cognitive development (Stewart, 2015). Most of the vocabularies are not only new but complex in terms of the concepts they describe. So from the very beginning of mathematics learning, it would appear that a learner has to have a very good understanding of the meanings of the symbols used, especially those that dealing with operations. Donna \& Hick (2017) argue that:

Learners meet these words only in a mathematical context and their meanings must be learnt from the teacher or the mathematics books. Mathematical words are unlikely to be used at home or in the child's everyday speech, Donna \& Hick (2017).

This notion calls for the teacher understanding and using mathematical vocabulary when teaching mathematics. It also suggests that books should be used in mathematics lessons not for merely copying exercises but reading and getting familiar with mathematics vocabularies. When writing questions, one should assure that the language used is not unnecessarily difficult. The questions must be stated unambiguous and emotionally neutral and demand as little reading and writing as possible. There are a variety of formats that can be followed for item writing. The open-ended question is the traditional type of question in which the learner must make his own response. Analysis of responses gives the tester insight into the learner's thought processes.

Example: Solve for $\mathrm{x}$ if $3 \mathrm{x}-6=6$.

Open-ended questions can pose problems if they are not formulated carefully. If one should, for example, ask to explain the meaning of a certain term, this may be too demanding for learners even though they might have a genuine understanding of the term. Better would be to formulate a mathematical question which is straightforward, involving the term concerned.

Example: What is the product of 4 and 7 ? is a much better question than asking the learners to explain what is meant by the term product?

Open-ended questions have the advantage that the teacher can exactly see how the learner reasons and follow his thought processes. The main disadvantage is that the scoring of tests with this type of question constitutes a relatively long and time-consuming activity. The teacher has to check every step in solutions of the problems. If it is kept in mind that five questions of each type is preferred, these tests are usually long to ensure completeness (validity). For example, if the subdomain is addition of whole numbers, five questions with single digit numbers and answers must be included as well as five questions with single digit numbers and two digit answers; two digit numbers and answers; Different combinations of the same numbers should also be included to make provision for the commutative property e.g.

A learner may know that $4+7=11$ but the same learner may fail with $7+4=$

My concern is how language of instruction enhances learners' learning of mathematical concepts through words and symbols. 


\section{Language and mathematics with young children}

My concern here is about communicating mathematical concepts as it relates to bilingual children in Gauteng. Discussing this concern is essential because, my study was conducted, among the third grades of the Foundation Phase schools in Gauteng Province. In Gauteng Province, children enter the Foundation Phase school at the age of 6 and are expected to be in grades three and four at the ages of 9 and 10 respectively. My concern is that although psycho linguists do not agree on how children acquire language, they all agree that this is the time children struggle to learn the basics of language use. They may not hold a discussion because they will not have developed the language needed to express logical thinking; they may not give reasons for their actions. It is for these reasons that sustaining a discussion with learners in such classes as grade 3 and 4 may be quite challenging.

In South Africa, many children enter school when they are bilingual, especially whose home language is not a national or official language and also belong to minority language communities (Morgan (2000). In most cases, they speak a home, a regional or national and an official language which, is usually a foreign language.

According to Morgan (2000) infant or child bilingualism is different from adult bilingualism. He argues that child bilingualism implies successive acquisition of two languages, first within the family and then through other community members (Martin 2007) and usually they acquire both their languages with a native or native-like pronunciation. Adult bilinguals (teachers who acquire their bilingualism while adults) usually speak their second language with a non-native accent (Martin 2007).

This difference in degrees of bilingualism between teachers and learners account for the communication problems in the classroom. Children may know the words in one language but fail to apply them correctly in the classroom. For example, children may first learn words for opposites but use them interchangeably. Teachers and learners may use the same words but with different meanings. Teaching words in mathematics is complex; it has to proceed in stages (Tooke, Hyatt, Leigh, Snyder \& Borda, 2015). Nevertheless, in most cases, as Phajane, (2017) argues, children are usually introduced to mathematics when children are still learning to use language, think and how the world around them works. While they could learn from their own experience bottom-up, the school provides learning topdown. Children use the language in getting to grips with mathematics and the adult language is" imposed" to increase precision.

\section{METHODS}

This study employed a qualitative approach and a case study design (Creswell, 2017). The methodology involved focus group discussions, interviews, mathematics vocabulary tests and classroom observations. The interviews and classroom observations were audio/video taped. Although case study design was used and qualitative approach in data collection, analysis and reporting.

In this study, the languages studied are English (L2) and Sepedi (LI) which are used, for instruction at various level of education in South Africa. The target sample includes mathematics teachers for Grade R to 3 from 2 Foundation Phase Schools, in the Mamelodi District of Gauteng Province of South Africa, Educational division of Gauteng Province. The issues studied include teachers' perception of the use of English and Sepedi in mathematics teaching; teachers' knowledge of mathematics vocabulary in Sepedi and in English, and finally the teachers' use of Sepedi and English in mathematics teaching. Coding systems developed by (Briggs, Cochran \& Gillett 2015) and developed further by Park, (2016) were adapted for use in analysing the transcripts from lessons and content analysis by the constant comparative approach was used to analyse transcripts from teacher interviews (Briggs, Cochran \& Gillett 2015). Simple descriptive statistics were used, to analyse teachers' knowledge about mathematics vocabulary equivalents and teacher perceptions about the use of Sepedi and English in mathematics teaching. It was felt useful to compare the teacher language patterns between Sepedi medium and English medium mathematics teaching, so as to assist policy makers on the formulation of language policy in education in Gauteng Province.

\section{RESEARCH QUESTION}

The data collection and analysis procedure is described and focuses on one of the research questions: Do teachers' perceptions of the use of Sepedi in mathematics teaching differ from their perceptions of the use of English in mathematics teaching? 


\section{FINDINGS AND DISCUSSIONS}

Given that we are drawing from a broad study that explored various aspects of Home Language use and Communication with young children in the Mathematics Classroom, we opted for the purpose of this paper, to report on teachers' responses and are discussed under relevant sub-headings below:

\section{Uncertainty about the medium of instruction in mathematics}

The language policy in education created hesitation about the medium of instruction in mathematics. For example, one teacher articulated a concern that, when Sepedi is used some learners experience problems when the medium of instruction changes to English in the Intermediate Phase classrooms. Teachers were concerned with language policy in education, which states that learners shall learn in the mother tongue or local languages from Grade R to 3, and learn in English thereafter (National Council for Curriculum and Assessment (NCCA) (2011). The use of Sepedi in teaching mathematics in Foundation Phase classrooms, did not prepare children for further education that was subsequently offered in English, in the intermediate phase.

One response was that, "The problem is that when children get to senior phase classrooms they face the problem of not understanding lessons in English because they are used to learning in Sepedi." Teachers' concern of which language (Sepedi or English) to use in mathematics was also revealed, through the analysis of data. Teachers indicated that they were not sure which language, Sepedi or English, should be used in mathematics teaching, as one teacher stated that, "It is difficult to say which language is suitable for mathematics teaching because some teachers cannot speak other languages." Teachers consider the limited number of languages that a teacher can speak fluently as a deciding factor for appropriateness of the language for classroom use.

\section{Introduction of English as medium of instruction for mathematics}

Teachers were concerned with late introduction of English as medium of instruction for mathematics. They indicated that English should be used in mathematics teaching early enough to prepare the learners for further education. The main reason was not for immediate understanding of mathematics, but because learners would be required to learn mathematics in English in the intermediate phase classrooms. This identifies a dilemma or tension caused by the contradiction between the immediate needs of learners to learn mathematics in a familiar language and the long-term needs of learners to develop competence in English. Teachers were also concerned with the time of the introduction of English medium to replace Sepedi as a medium of instruction. The present policy states that the English medium is introduced in grade three but teachers felt that, that was too late for preparing learners for learning English.

Delay in the introduction of English medium created concerns and pressures in the teachers' use of language in mathematics because teachers believed that learners could improve their English by using it in other subjects such as in mathematics. Teachers strongly believed that learners could not speak English because most of the lessons were conducted in Sepedi. Teachers felt that it would help such learners if they were introduced to English medium earlier than Grade four to improve their English as was regarded as Grade seven was far too late for learners to develop English language competence.

By this, teachers were referring to the preparation of learners for English as a language rather than mathematical language. The concern here is between the teachers' strong desire to improve learners' English and the need to make learners learn mathematics. Teaching mathematics through English at the same time teaching English through mathematics-seemed to be the alternative, though a difficult one.

In their perceptions teachers felt the classroom level must be considered for the use of Sepedi or English. Although they indicated the levels that were appropriate for the use of Sepedi or English, they did not agree on a particular classroom level. They indicated that teaching of mathematics in English should begin in Grade $\mathrm{R}$ to 3 . The issue here is an exemplification of teachers' inadequate knowledge of the role of language in mathematics teaching and learning.

\section{THE ACTIVE CLASSROOM DISCOURSE}

The concerns and pressures in the use of language came up vividly when teachers discussed the dynamics of the classroom discourse. 


\section{Teaching competence}

In the data, the concern for the teaching competence was expressed in two contradictory ways; teacher dedication and teacher confidence. Here, teacher dedication is used to describe a situation, where a teacher does not show personal commitment to teaching. From the data, it appears that some problems in using Sepedi in mathematics teaching, were perceived to be associated with teacher lack of dedication. One teacher expressed a concern that lack of dedication to duty when Sepedi is used; so teachers do not prepare adequately for using Sepedi in mathematics teaching. This view was expressed by one of the teachers in the sample. The problem is with the teachers. They are not dedicated to duty because learners have to know how to subtract from their teacher for example, a child who solves a subtraction problem this way:

85

$-29$

$\underline{64}$

may be applying an inappropriate rule always subtract the smaller number from the larger one to subtraction. So if the learners do not know it they have to be taught. However, when English is used, teachers feel the challenge to impress upon learners that they know English.

The second concern was that when Sepedi is used in mathematics teaching, teachers speak with confidence as they indicated that. The good thing is that you speak with confidence so that the learner will understand you and that the learner will pick it up quickly. Teaching with confidence and without dedication are conflicting reactions to the use of Sepedi as the two behaviours cannot occur together at the same time. This is a clear demonstration of another set of tensions in the use of language in mathematics that the use of a particular language makes some teachers become confident whereas other become less dedicated to the teaching process.

\section{Communication problem between the teacher and their learners}

What came up frequently during the interviews was that learners needed more help in English medium than in Sepedi medium lessons because of communication problems. Supporting this, I repeatedly saw teachers whispering to learners in Sepedi during English medium lessons. Those who whispered to the learners indicated that they whispered in Sepedi because they wanted learners to understand what was said. They argued that:

In English medium lessons, I was helping them because they did not understand what to do. They did not know what to do. I should say they did not understand what I instructed them to do. That is why I was helping the learners to answer the questions. They were able to answer in English but with difficulty.

Teachers thus felt that the Sepedi medium mathematics lessons were more successful than the English medium mathematics lessons. Some of the responses were that; the one in Sepedi was the most successful lesson because children were more relaxed because in the past they were learning mathematics in Sepedi. The success of a lesson was based on how easy or difficult teachers communicated with learners.

Teachers also felt that learners were livelier and more involved in Sepedi medium lessons than in English medium lessons because lessons were contributing to the classroom talk in Sepedi medium more than in the English medium lessons. Teachers felt that learners were contributing to the classroom talk in the Sepedi medium mathematics lessons because Sepedi is their mother tongue. Some teachers felt that in the Sepedi medium lesson, learners were able to answer questions.

\section{Language code switching and mixing}

The analysis of data revealed that there are concerns about whether teachers use Sepedi or English or mathematical language in mathematics resulting in them using a mixture of Sepedi and English. I have chosen to call the mixture of Sepedi and English tri-lingual code switching because terms from ordinary Sepedi, ordinary English and mathematical discourse, are used in the same context. However, during focus group discussions, teachers felt that code switching between Sepedi and English was the only way to cope with language use in mathematics teaching for the reason that Sepedi is a common language whereas English is a language more suitable for the technical demands of mathematics teaching. Teachers used English especially when they could not find some mathematical terms in Sepedi and so I try to discuss them in a mixture of Sepedi and English. Words such as circle, triangle and quadrilateral are in English but written with Sepedi spelling as sediko, khutlotharo and khutlonne. 
Another cause for code switching was that it is appropriate to combine English with Sepedi when teaching mathematics in Grade 3 and 4 so that when they (learners) get to Grade 5, they will not have any problem learning mathematics in English. This finding suggests that using two different languages as a medium for instruction though at different levels of education tends to create tension in teachers' use of language in mathematics.

Language code switching between Sepedi and English, is perceived as a solution to language problems in the classroom. Some teachers felt that mixing the two languages would yield a better lesson delivery than using any single language. Nka dira eng gape? Bokaone ke fetogele go Sepedi (which means that what else can I do? I simply switch between Sepedi and English. By 'nka dira eng gape' signifies teacher's helplessness in the use of language in an active classroom discourse. It appears that teachers use language code switching as a coping strategy to deal with an active classroom discourse an indication of tension.

Teachers felt that they found it easier to communicate with the learners in Sepedi medium than in the English medium lessons for a number of reasons. First, because learners are used to learning in Sepedi. After all, I always teach them in Sepedi. Second, learners were more fluent in Sepedi than in English. Most of the learners speak Sepedi so that they could understand the lesson more quickly than in English. I did not need to repeat. Learners were able to understand once because they know, I did not need to simplify the words.

There were also learners, who could not speak English. Those who have a very poor educational background experience a lot of problems, but those living in town, are lucky in that they attended preschool where they learn English. These children, who speak good English than those who never went to preschool. Teachers demonstrated lack of experience in the use of both Sepedi and English and they switched between languages in both Sepedi and English medium classrooms, there were differences in some elements of the active classroom discourse between them. For example, in Sepedi medium lessons, learners' contribution to classroom talk was high and language competence for both the teacher and learners was high. However, when English was used, learners needed more help in how to speak. Despite all this, teachers feared that the use of Sepedi lowered the teaching of mathematics in English.

\section{Contradiction of instructional languages}

I use the terminology contradiction of instructional languages to refer to the languages used in writing instructional materials including the lesson plans and the language used for delivering the lesson in the classroom. Teachers were concerned with contradiction of instructional languages in that when Sepedi was used in mathematics teaching, teachers found that preparing a mathematics lesson in English and presenting it in Sepedi was quite challenging for a mathematics teacher. Specifically, the pressure arose as teachers shift from Sepedi to English and back as they prepare and deliver the lesson. The shifting between the languages required that teachers find enough mathematical vocabulary equivalents.

Preparing a mathematics lesson using a Teacher's Guide written in English and the corresponding Learners' Book in Sepedi worsened the pressures. One of the teachers' responses was:

I think that somehow preparation is a problem because of the textbooks, which are written in Sepedi and the corresponding teachers' guide is in English. We prepare in Sepedi but write a lesson plan in English and teach it in Sepedi; because of the differences in the two books we have problems to teach in Sepedi.

This implies that there is a need for language code switching during teacher preparation for lessons partly because of the instructional materials and partly the mysterious language policy in education instilled by language ineffectiveness.

\section{Limiting the range of languages for instruction}

Limiting the range of languages for use in mathematics teaching refers to the need for lower numbers of languages used by teachers. This formed an essential part of teachers' thinking. This occurred on two fronts to avoid confusing learners and because some teachers know one local language only. To this effect, it was frequent to hear teachers say that Sepedi should be used in mathematics teaching, as introducing another language would only confuse learners. Furthermore, some teachers do not know other local languages apart from Sepedi. Some of those interviewed stated:

In this area, some young children are Ndebeles. So for me it is difficult to speak their language that can help them understand mathematics, as I don't speak Ndebele but isiZulu only.

The two, however, are entwined and the main focus is that teachers are not comfortable when more than one language is used as a medium of instruction in mathematics teaching. Teachers felt that limiting the range of languages would perhaps reduce the pressures and concerns experienced during the use of language in mathematics teaching. 


\section{Teaching mathematics through language}

The second predicament concerns teachers' choice between teaching mathematics through a language and teaching language through mathematics. Teachers were aware that one of their roles was to make learners understand mathematics. To achieve these roles, teachers are expected to pay more attention to the mathematical discourse than perhaps the classroom discourse (language of instruction). However, mathematical content exists in a highly specialised language the language for communicating mathematical concepts. Teachers experience a predicament when it comes to deciding whether to teach mathematical content to teachers who have no language for communicating the content.

\section{To code switch between Sepedi and English}

Language code switching is another manifestation of dilemma in classroom discourse in two ways. First, the teachers' tendency that mathematical concepts can best be described in English and not in Sepedi, they are at pains to use the appropriate English terms. Second, teachers had to choose between using English terms with English spelling or Sepedi spellings although terms were pronounced in English. Such terms were used even where plausible Sepedi equivalents were available to the teachers. In most cases when teachers were asked to give a Sepedi equivalent to English term they would spontaneously give an artificial word and only when they were asked again would they give a Sepedi equivalent.

It is possible that teachers are gradually losing the Sepedi mathematical terms because of not using them or because of the feeling that the Sepedi terms do not describe the mathematical terms with sufficient precision. However, most of them were able to remember enough terms to be able to discuss mathematics in Sepedi. This may signify gradual replacement of the use of local language in mathematics teaching by the English terms representing a language shift.

\section{To teach mathematics in Sepedi or in English}

The findings show that teachers gave more Sepedi to English mathematical vocabulary equivalents than English to Sepedi mathematical vocabulary. This suggests that the teachers' knowledge of mathematical vocabulary was more limited in Sepedi than in English. This pattern has implications on how teachers use Sepedi or English in mathematics teaching. The difference in teachers' knowledge of equivalents of mathematical vocabularies suggests that teachers are likely to use more English terms than Sepedi when teaching mathematics in Sepedi medium lessons. Considering that learners do not speak English, this tendency is likely to create dilemmas in the teachers who find more mathematics vocabulary terms in English than in Sepedi, the dilemma of whether to teach mathematics in English or teach learners in Sepedi.

\section{The difference between the language in instructional materials and the learners' teachers' competencies in the instructional language}

The difference between the language in instructional materials and teacher or learners' language competence in the medium of instruction creates another tension in teachers' use of language in mathematics teaching. On instructional materials, teachers were concerned with language use in the textbooks for mathematics. Teachers were not sure whether textbooks prepared in English or in Sepedi provide distorted information about mathematics and in so doing confused the learners. Yet they strongly agree that using Sepedi and not English distorts the meaning of mathematical concepts. This is because with the use of one set of textbooks for mathematics, teachers were not able to assess the language influence of the books on mathematics. However, it was possible to assess the language influence from the everyday use of language and mathematical language in mathematics discourse.

Although teachers agreed that, in most cases, it is difficult to understand mathematical concepts because the Learner's Book is written in Sepedi while the Teacher's Guide is in English, they strongly agreed that both Learners' Book and the corresponding teacher's guide should be written in English and not in Sepedi. However teachers were divided on whether there were no reference books for mathematics that could help teachers use Sepedi or English in mathematics teaching. Although teachers were not sure that there are fewer numbers of textbooks for mathematics written in both Sepedi and English, they tended to agree more for English medium than for Sepedi medium. Therefore, the books that are available for use in schools tend to exert pressure on which language to use in mathematics teaching. 


\section{DISCUSSION and CONCLUSIONS}

The main purpose of this study was to investigate how teachers use home language in mathematics teaching. Comparison was made among teachers and between Sepedi medium and English medium mathematics lessons in Foundation Phase schools in Gauteng Province. Problems explored in the study included teacher mathematics vocabulary, teacher perceived prospects and constraints in the use of Sepedi and English in mathematics teaching and teacher use of language in mathematics lessons. The results of the study showed that mathematics teachers experience different problems and tensions in the use Sepedi or English and the degree of problems and tensions are different between Sepedi and English. There are distinct sources of problems and tensions, which include the linguistic nature of mathematics, the confusing language policy in education, the dynamics of classroom discourse and contradiction in the sources of language for use in mathematics.

The problems and tensions result in teachers emphasising some uses of language more than others. Based on the research findings, it is recommended that a plan be developed, to identify the problems and tensions in teachers in the use of language in mathematics teaching and find solutions to the problems. Further research should be conducted not only in South Africa but also in the African continent.

\section{REFERENCES}

Adler, J. (2001). Teaching Mathematics in Multilingual Classrooms. Dordrecht: Kluwer Academic Publishers.

Amador, J., \& Weiland, I. (2015). What preservice teachers and knowledgeable others professionally notice during lesson study. Teacher Educator, 50(2), 109-126.

Bressoud, D. M., Mesa, V., \& Rasmussen, C. L. (Eds.). (2015). Insights and recommendations from the MAA national study of college calculus. Washington, DC: Mathematical Association of America.

Briggs, W., Cochran, L., \& Gillett, B. (2015). Calculus: Early transcendentals (2nd ed.). Boston, MA: Pearson.

Creswell, J. W. (2017). Educational Research: Planning, conducting, and evaluating quantitative and qualitative research. 4 th edition.

Department of Basic Education. (2012). Status of the Language of Learning and Teaching (LoLT) in South African public schools. Pretoria: DBE.

Donna, J. D., \& Hick, S. R. (2017). Developing elementary preservice teacher subject matter knowledge through the use of educative science curriculum materials. Journal of Science Teacher Education, 28(1), 92-110.

Hunter, R. 2005. Reforming communication in the classroom: One teacher's journey of change. In: Clarkson, P. et al., eds. Building connections: Research, theory and practice (Proceedings of the 28th annual conference of the Mathematics Education Research Group of Australasia, pp. 451458). Sydney: MERGA.

Males, L., Earnest, D., Dietiker, L., \& Amador, J. (2015). Examining K-12 prospective teachers' curricular noticing. In T. G. Bartell, K. N. Bieda, R. T. Putnam, K. Bradfield, \& H. Dominguez (Eds.), Proceedings of the 37 th annual meeting of the North American chapter of the International Group for the Psychology of Mathematics Education (pp. 88-95). East Lansing, MI: Michigan State University.

Martin, T. S., ed. 2007. Mathematics teaching today: Improving practice, improving student learning, 2nd ed. Reston, VA: National Council of Teachers of Mathematics.

Morgan, C. (2000). Language in use in mathematics classrooms: developing approaches to a research domain. Book Review. Educational Studies in Mathematics, Vol. 41, 9399.

National Council for Curriculum and Assessment (NCCA) (2011). Better literacy and numeracy for children and young people: NCCA submission, February 2011. Dublin: Author.

Park, J. (2016). Communicational approach to study textbook discourse on the derivative. Educational Studies in Mathematics, 91, 395-421.

Phajane, MH. (2017). Teaching the basics in the Foundation Phase schools: Reading, writing and numeracy in Realigning Teacher Training in the $21^{\text {st }}$ Century. Cengage learning. Edited by MD Magano, JC Mohapi and D Robinson. ISBN: 978-1-4737-3351-0.

Piaget. J. (1997). Development and learning, in Reading on the development of children, edited by $\mathrm{M}$ Gauvin \& M Cole. New York: Scientific American: 20-28.

Schiffman, H. R. (2000). Sensation and Perception: An Integrated Approach. New York: John Wiley and Sons Inc. 
Sintema, E. J., \& Phiri, P. A. (2018). An investigation of Zambian mathematics student teachers' technological pedagogical content knowledge (TPACK). Journal of Basic and Applied Research International, 24(2), 70-77.

Stewart, J. (2015). Single variable calculus: Early transcendentals (8th Ed., Vol. 2). Boston, MA: Cengage Learning.

Stipek, D. J., Oivvin, K. B., Salmon, J. M. and MacGyners, V. L. (2001) Teachers' beliefs and practices related to mathematics instruction. Teaching and Teacher Education, Vol. 17 (2), pp 213 - 226.

Thompson, P. W. (2016). Researching mathematical meanings for teaching. In English, L., \& Kirshner, D. (Eds.), Handbook of International Research in Mathematics Education (pp. 435-461). London: Taylor and Francis.

Tooke, D, Hyatt, B., Leigh, M., Snyder, B., \& Borda, T. (2015). Why aren't manipulatives used in every middle school mathematics classroom? Middle School Journal. 24(2). pp. 61-62.

Vygotsky, L. S. (1995). Thought and language. Cambridge, MA: M.I.T. Press.

Yackel, E.; Cobb, P.; Wood, T. 1998. The interactive constitution of mathematical meaning in one second grade classroom: An illustrative example. Journal of Mathematical Behaviour, vol. 17, no. 4, pp. 469-488. 